\title{
Use of Information Sources on Vaccine-Preventable Diseases in Pregnant Women: An Experience in Ferrara, Italy
}

\author{
Giovanni Gabutti ${ }^{1}$ **(D), Umberto Carioli ${ }^{2}$, Diego Gamberoni ${ }^{2}$, Giulia Masetti ${ }^{2}$, Giulio Matteo ${ }^{2}$, \\ Paola Perrone ${ }^{2}$, Rosaria Cappadona ${ }^{3}$, Pantaleo Greco ${ }^{3}$, Roberta Siliquini ${ }^{4}$ and Armando Stefanati ${ }^{1}$ \\ 1 Department of Medical Sciences, University of Ferrara, 44121 Ferrara, Italy; armando.stefanati@unife.it \\ 2 Postgraduate School of Hygiene and Preventive Medicine, University of Ferrara, 44121 Ferrara, Italy; \\ umberto.carioli@unife.it (U.C.); diego.gamberoni@unife.it (D.G.); giulia.masetti@unife.it (G.M.); \\ giulio.matteo@unife.it (G.M.); paola.perrone@unife.it (P.P.) \\ 3 Department of Morphology, Surgery and Experimental Medicine, Section of Obstetrics and Gynecology, \\ Azienda Ospedaliero-Universitaria S. Anna, University of Ferrara, 44121 Ferrara, Italy; \\ rosaria.cappadona@unife.it (R.C.); pantaleo.greco@unife.it (P.G.) \\ 4 Department of Public Health Sciences and Pediatrics, University of Turin, 10126 Turin, Italy; \\ roberta.siliquini@unito.it \\ * Correspondence: giovanni.gabutti@unife.it; Tel.: +39-0532-455568; Fax: +39-0532-205066
}

Received: 19 November 2019; Accepted: 23 December 2019; Published: 28 December 2019

\begin{abstract}
The "vaccine hesitancy" and the consequent lowering of vaccination coverage have, on one hand, pushed the Italian government to reintroduce some new compulsory vaccinations for access to schools and, on the other, have imposed a greater effort on health operators to understand the causes and, consequently, to intervene with tools for promotion and health education. In Ferrara, we administered 201 non-self-filling questionnaires to 201 pregnant women within a cross-sectional multicenter study, consisting of 63 items divided into 7 sections. In particular, we wanted to investigate the correlation between the socio-demographic characteristics of the interviewees and the sources used to obtain information and, on the other side, the intention to vaccinate in relation to the perception of the diffusion and of the risk of vaccine-preventable diseases. The institutional information sources are less used by foreigners, primiparous, and women with a low education level. The perception of the severity of vaccine-preventable diseases was greater in those inquiring from institutional sources. In a public health perspective, knowing the profile of future mothers in terms of socio-demographic characteristics and of the quality of the used information channels may help to guide the choices of communication in the vaccination field.
\end{abstract}

Keywords: vaccine hesitancy; pregnancy; paediatric vaccination; vaccine

\section{Introduction}

Vaccines have allowed to prevent at least 10 million deaths between 2010 and 2015 [1] and the World Health Organization (WHO) estimates that immunization in the first decade of the 21st century prevented 2.5 million deaths every year in the world among children aged $<5$ years. Increasing immunization rates is an item on a list of ten public health achievements of the Center for Disease Control and Prevention (CDC) to improve life expectancy [2]. The Global Vaccine Action Plan 2011-2020 (GVAP), which was endorsed by all the WHO Member States at the 65th World Health Assembly in May 2012, described the immunization framework to prevent millions of deaths by 2020. The aim of GVAP 2011-2020 is also to guarantee the benefits of immunization, with a world perspective, to all people without any discrimination [3]. 
The European Vaccine Action Plan 2015-2020 (EVAP) attempts to reach GVAP's goals in the WHO European Region. Unfortunately, the plan did not reach the targets and this area continues not be measles- and rubella-free [4].

The Italian document that acquires the European suggestions is the National Immunization Plan (Piano Nazionale Prevenzione Vaccinale, PNPV) 2017-2019, which recommends to keep immunization coverage in childhood at least at $95 \%$ against diphtheria, tetanus, pertussis, hepatitis B, Haemophilus influenzae type $b$, poliomyelitis, pneumococcus, meningococcus $C$, chickenpox, rotavirus, and the first dose of MMR (measles, mumps, and rubella) and HPV vaccine in both sexes at 12 years of age [5].

Considering the not optimal achievement of the coverage targets, their gradual decline in recent years, and the re-emerging outbreaks of measles [5-7], the Italian government introduced new mandatory vaccinations on 31 July 2017. In detail, the law 119/2017 [8] identifies ten mandatory vaccines for infants: diphtheria, tetanus, poliomyelitis, hepatitis B virus (all of which were already compulsory) plus pertussis, Haemophilus influenzae type $b$, measles, mumps, rubella, and varicella. Data related to the first six months since the application of this law showed an increasing immunization coverage for both mandatory and recommended immunizations [9].

Pregnant women play a key role because their opinion on and compliance to immunization indirectly affect the paediatric immunization coverage. A quite recent review suggests that parents have difficulties to identify impartial and reliable sources of information in order to obtain answers to their doubts on this specific topic [10].

One of the most common self-reported parent's reasons that cause vaccination refuse or delay is the fear of vaccine-related adverse events and a low perception of infection's risk related to vaccine-preventable diseases [11].

An experimental study points out that involving parents in focused meetings leads to a greater increase in paediatric vaccination if compared with self-reading information [12]. Furthermore, observational studies reveal that the web and health workers are the main sources of information used by pregnant women [13]. For this reason, there is an increasing attention to information available on the web, which anyway offers both misleading and evidence-based content [14].

In this context, efforts were made to create and improve institutional websites designed to spread scientific information on vaccines and immunization [15].

To better answer to health needs, it is necessary to overcome the concept of "vaccination consenting" or "refuser". In 2012, the Strategic Advisory Group of Experts (SAGE) defined "vaccine hesitancy" as an attitude: "to delay in acceptance or refusal of vaccination despite availability of vaccination services ... influenced by factors such as complacency, convenience and confidence " [16].

The hesitant individuals are a heterogeneous group spreading between the range of total acceptance and categorical refusal. Within this continuum, those who are hesitant have a heterogeneous behavior. Gust D. et al. found that even if seriously concerned about vaccination parents are a low percentage, the remaining part, even if supportive, has some doubt about immunization safety [17].

In this perspective it is important to understand where and how people take information with the aim of spreading scientifically based information. A cross-sectional multicentre study (NAVIDAD study) examined the determinants of acceptance of mandatory vaccine restoration, identifying one of the main factors in information sources [18]. A subsequent analysis from the same working group focused on awareness and confidence in immunization [19]. In the context of the Navidad study, we analysed the use of information sources by pregnant women in the province of Ferrara.

\section{Materials and Methods}

The study was approved by the Ethics Committee of Ferrara's province (Ethical Project Identification Code: 160890), as part of a national cross-sectional multicentre study; the cities involved, in addition to Ferrara, were Turin (chief unit), Bologna, Milan, Parma, Ancona, Perugia, Roma, Siena, Catania, Chieti-Pescara, L'Aquila, Messina, and Naples. 
During the period of November 2016-May 2017, we enrolled pregnant women, $>18$ years of age, who were asked to fill in a questionnaire. The women had to be able to understand the protocol information, in order to obtain an informed consent, and the questionnaire. Subjects of our sample were selected among patients waiting for a gynaecological visit, ultrasound, or other examinations at Ferrara's University Hospital (which is the public Hospital of the city) and at the gynaecological counselling centre.

Before the interviews, we fully explained the aim of our study and, after that, we obtained the informed consent.

The interviews, lasting about $25 \mathrm{~min}$, were conducted by trained resident doctors.

We administered a non-self-compiling questionnaire composed by seven sections for a total of 63 items [18]. Each section investigated the following topics:

1. Socio-demographic features (age, schooling, nationality, and so on);

2. Intention to vaccinate and for which pathologies;

3. Sources used to obtain informations about immunization;

4. The degree of confidence in healthcare workers;

5 . The perception of the frequency and severity of the major vaccine-preventable diseases;

6. Vaccine knowledge;

7. The opinion on the restoration of mandatory vaccines for the admission to nursery and school.

This study focuses on the third section of the questionnaire, which investigates the sources through which the women had obtained information about vaccinations; in particular, we investigated how the choice of different kinds of sources (Section 3) is influenced by socio-demographic framing (Section 1) and how these sources influence the perception of the severity of the major vaccine-preventable diseases (Section 5).

A total of 201 questionnaires were collected and data were processed using IBM SPSS Statistics for Windows, Version 25.0. Armonk, NY: IBM Corp.. The variables included in the analysis were the following: socio-demographic data (previous delivery, marital status, nationality, education level, employment, age), the pregnancy quarter, the perception of severity of the major vaccine-preventable diseases (hepatitis B, poliomyelitis, Haemophilus Influenzae type B, tetanus, diphtheria, pertussis, measles, rubella, mumps, meningitis, varicella, and human papilloma virus), and the used information sources.

The perception of severity of the major vaccine-preventable diseases was classified as follows on the basis of the answer to the question, "how much do you consider dangerous the following disease?": severe (including the answers in the questionnaire "very severe" and "quite severe") and not severe (including the answers "not severe at all", "a little severe", and "no answer").

The sources used by women to seek and obtain information about vaccinations were classified in "institutional sources" (general practitioner, gynaecologist, paediatrician, information leaflets from the Ministry of Health or the healthcare services, vaccination clinics, institutional websites, birthing classes) and "not institutional" (not institutional websites, applications for smartphone or tablet, clinicians not working for public health service, word of mouth through relatives and friends, mass media, anti-vaccine movements). We divided our sample into "women who received information from at least two institutional sources" and "women who received one or none information from institutional sources" in order to investigate, by a bivariate analysis, the association between the used information source and the perception of severity of the vaccine-preventable diseases.

A multivariate logistic regression model has been estimated, considering the source of information (institutional or not institutional) as the dependent variable and the socio-demographic variables as covariates (previous delivery, marital status, nationality, education level, employment, quarter of pregnancy and age). About delivery we consider the difference between women who had at least one previous delivery and nulliparity; about education between "high level" (if they had a college degree or high school), and "low level" (if they have a lower degree than high school); about employment we consider the difference between unemployed and employed; about the age we divided the sample around the average age of the Italian pregnant women (33 years) reported by the CEDAP (Certificato di 
assistenza al parto/Birth attendance certificate) [20]. All variables investigated in the socio-demographic part of the questionnaire were included in the logistic regression model, independently from its statistical significance.

These associations are expressed as odds ratios (OR) with a 95\% confidence interval (CI), a $p$-value $\leq 0.05$ was considered significant for all analyses.

\section{Results}

A total of 201 pregnant women were interviewed, and their filled in questionnaires were collected. The socio-demographic characteristics of the sample are described in Table 1.

Table 1. Socio-demographic characteristics of the sample.

\begin{tabular}{|c|c|c|c|}
\hline & & $n$ & $\%$ \\
\hline \multirow{6}{*}{ Age (years) } & $\leq 20$ & 4 & 2.0 \\
\hline & $21-25$ & 9 & 4.5 \\
\hline & $26-30$ & 50 & 24.9 \\
\hline & $31-35$ & 60 & 29.9 \\
\hline & $36-40$ & 58 & 28.9 \\
\hline & $>40$ & 20 & 10.0 \\
\hline \multirow{2}{*}{ Previous delivery } & One or more & 55 & 27.4 \\
\hline & None & 146 & 72.6 \\
\hline \multirow{2}{*}{ Nationality } & Italian & 187 & 93.0 \\
\hline & Foreign & 14 & 7.0 \\
\hline \multirow{2}{*}{ Marital status } & Cohabiting/married & 190 & 94.5 \\
\hline & Single/divorced & 11 & 5.5 \\
\hline \multirow{3}{*}{ Education level } & College degree & 95 & 47.3 \\
\hline & High school & 87 & 43.3 \\
\hline & Lower than high school & 19 & 9.5 \\
\hline \multirow{3}{*}{ Quarter of pregnancy } & First & 26 & 12.9 \\
\hline & Second & 38 & 18.9 \\
\hline & Third & 137 & 68.2 \\
\hline \multirow{6}{*}{ Employment } & Office workers or teachers & 85 & 42.3 \\
\hline & Entrepreneurs or freelance professionals & 18 & 9.0 \\
\hline & Labourers or artisans & 19 & 9.5 \\
\hline & Healthcare professional & 27 & 13.4 \\
\hline & Unemployed & 41 & 20.4 \\
\hline & Other & 11 & 5.5 \\
\hline
\end{tabular}

The average age of the sample was equal to 33.5 years (32.6 years for primiparous); only $6.5 \%$ of women were aged 25 or under, while $10 \%$ were $>40$ years old. A total of $72.6 \%$ (146) of the respondents faced their first pregnancy. Only 7\% were foreigners, and 190 (94.5\%) were married or life-partners.

Regarding the educational qualification, 95 women (47.3\%) were graduates, $87(43.3 \%)$ had a high school degree, and 19 (9.5\%) had a lower degree.

Most of the interviewed women were in the third quarter of pregnancy $(68.2 \%)$ as most questionnaires were administered in outpatient facilities, where there were also places for pre-natal courses, or in clinics dedicated to term pregnancies.

$20.4 \%$ of the sample was composed by unemployed women; most (42.3\%) were office employers or teachers, $13.4 \%$ were healthcare workers.

The use of institutional information sources concerning vaccination is shown in Table 2. 
Table 2. Association between socio-demographic data and vaccine information from institutional sources. OR, odds ratio; $\mathrm{CI}$, confidence interval.

\begin{tabular}{|c|c|c|c|c|c|c|c|}
\hline & & \multicolumn{6}{|c|}{ Vaccination Information from Two Institutional Sources at least } \\
\hline & & OR & $95 \% \mathrm{CI}$ & $p^{* *}$ & Adj OR* & $95 \%$ CI & $p^{* *}$ \\
\hline \multirow{2}{*}{$\begin{array}{l}\text { Previous } \\
\text { delivery }\end{array}$} & One or more & 1000 & & & 1.000 & & \\
\hline & None & 0.078 & $0.033-0.186$ & $<0.001$ & 0.042 & $0.014-0.122$ & $<0.001$ \\
\hline \multirow{2}{*}{$\begin{array}{l}\text { Marital } \\
\text { status }\end{array}$} & Cohabiting/married & 1000 & & & 1.000 & & \\
\hline & Single/divorced & 0.367 & $0.095-1.426$ & 0.148 & 0.336 & $0.069-1.634$ & 0.176 \\
\hline \multirow{2}{*}{ Nationality } & Italian & 1000 & & & 1.000 & & \\
\hline & Foreign & 0.489 & $0.161-1.487$ & 0.208 & 0.213 & $0.046-0.980$ & 0.047 \\
\hline \multirow{2}{*}{$\begin{array}{c}\text { Education } \\
\text { level }\end{array}$} & High level & 1000 & & & 1.000 & & \\
\hline & Low level & 0.571 & $0.215-1.515$ & 0.260 & 0.197 & $0.049-0.790$ & 0.022 \\
\hline \multirow{2}{*}{ Employment } & Unemployed & 1000 & & & 1.000 & & \\
\hline & Employed & 0.906 & $0.456-1.800$ & 0.778 & 0.604 & $0.250-1.457$ & 0.262 \\
\hline \multirow{2}{*}{$\begin{array}{l}\text { Quarter of } \\
\text { pregnancy }\end{array}$} & First or second & 1000 & & & 1.000 & & \\
\hline & Third & 1261 & $0.695-2.287$ & 0.445 & 1.769 & $0.824-3.796$ & 0.143 \\
\hline \multirow{2}{*}{ Age (years) } & $<33$ & 1,000 & & & 1.000 & & \\
\hline & $\geq 33$ & 1,271 & $0.722-2.237$ & 0.405 & 1.062 & $0.535-2.106$ & 0.864 \\
\hline
\end{tabular}

Statistically significant results are reported in bold. * Adjusted age, marital status, nationality, educational level, employment, quarter of pregnancy, previous delivery. ${ }^{* *}$ Significance level $p<0.05$.

Women showing a lesser probability to use institutional sources are primiparous (Adj OR: 0.042, 95\% CI: 0.014-0.122, $p<0.001$ ), foreign (Adj OR: 0.213, 95\% CI: 0.046-0.980, $p=0.047$ ), and with a low level of education (Adj OR: 0.197, 95\% CI: 0.049-0.790, $p=0.022$ ). Women $\geq 33$ years of age and women who were in the third quarter at the time of the interview showed a greater tendency to use institutional sources, although these data have no statistical significance.

Table 3 shows how the perception of risk related to the main vaccine-preventable diseases is influenced by the type of used source of information: institutional or non-institutional. The analysis underlines that the perception of the risk related to vaccine-preventable diseases is overall greater among women using institutional sources to obtain information. In detail, it emerges that, for poliomyelitis, Haemophilus influentiae type b, diphtheria, pertussis, and rubella, the difference between the two groups of women is statistically significant.

Table 3. Perception of risk related to vaccine-preventable infectious disease according to the type of information source: institutional or non-institutional.

\begin{tabular}{|c|c|c|c|c|c|c|c|}
\hline & \multirow{3}{*}{$\begin{array}{c}\text { Disease } \\
\text { Dangerousness } \\
\text { Perception }\end{array}$} & \multicolumn{4}{|c|}{$\begin{array}{l}\text { Vaccination Information from two } \\
\text { Institutional Sources at least }\end{array}$} & \multirow[b]{3}{*}{ OR } & \multirow[b]{3}{*}{$p^{*}$} \\
\hline & & \multicolumn{2}{|c|}{ Yes } & \multicolumn{2}{|c|}{ No } & & \\
\hline & & $n$ (=99) & $\%$ & $n(=102)$ & $\%$ & & \\
\hline \multirow{2}{*}{ Hepatitis B } & Yes & 94 & 50.5 & 92 & 49.5 & \multirow[t]{2}{*}{1.644} & \multirow[t]{2}{*}{0.200} \\
\hline & No & 5 & 33.3 & 10 & 66.7 & & \\
\hline \multirow{2}{*}{ Poliomyelitis } & Yes & 92 & 53.2 & 81 & 46.8 & \multirow[t]{2}{*}{7.656} & \multirow[t]{2}{*}{0.006} \\
\hline & $\mathrm{No}$ & 7 & 25.0 & 21 & 75.0 & & \\
\hline \multirow{2}{*}{$\begin{array}{l}\text { Haemophilus } \\
\text { influenzae b }\end{array}$} & Yes & 40 & 67.8 & 19 & 32.2 & \multirow[t]{2}{*}{11.489} & \multirow[t]{2}{*}{0.001} \\
\hline & No & 59 & 41.5 & 83 & 58.5 & & \\
\hline \multirow{2}{*}{ Tetanus } & Yes & 90 & 50.8 & 87 & 49.2 & \multirow[t]{2}{*}{1.506} & \multirow[t]{2}{*}{0.220} \\
\hline & No & 9 & 37.5 & 15 & 62.5 & & \\
\hline \multirow{2}{*}{ Diphtheria } & Yes & 74 & 54.4 & 62 & 45.6 & \multirow[t]{2}{*}{4.477} & \multirow[t]{2}{*}{0.034} \\
\hline & No & 25 & 38.5 & 40 & 61.5 & & \\
\hline \multirow{2}{*}{ Pertussis } & Yes & 75 & 54.7 & 62 & 45.3 & \multirow[t]{2}{*}{5.190} & \multirow[t]{2}{*}{0.023} \\
\hline & No & 24 & 37.5 & 40 & 62.5 & & \\
\hline
\end{tabular}


Table 3. Cont.

\begin{tabular}{|c|c|c|c|c|c|c|c|}
\hline & \multirow{3}{*}{$\begin{array}{c}\text { Disease } \\
\text { Dangerousness } \\
\text { Perception }\end{array}$} & \multicolumn{4}{|c|}{$\begin{array}{l}\text { Vaccination Information from two } \\
\text { Institutional Sources at least }\end{array}$} & \multirow[b]{3}{*}{ OR } & \multirow[b]{3}{*}{$p^{*}$} \\
\hline & & \multicolumn{2}{|c|}{ Yes } & \multicolumn{2}{|c|}{ No } & & \\
\hline & & $n(=99)$ & $\%$ & $n(=102)$ & $\%$ & & \\
\hline \multirow{2}{*}{ Measles } & Yes & 72 & 53.3 & 63 & 46.7 & \multirow[t]{2}{*}{2.738} & \multirow[t]{2}{*}{0.098} \\
\hline & No & 27 & 40.9 & 39 & 59.1 & & \\
\hline \multirow{2}{*}{ Rubella } & Yes & 76 & 54.7 & 63 & 45.3 & \multirow[t]{2}{*}{5.301} & \multirow[t]{2}{*}{0.021} \\
\hline & No & 23 & 37.1 & 39 & 62.9 & & \\
\hline \multirow{2}{*}{ Mumps } & Yes & 61 & 51.7 & 57 & 48.3 & \multirow[t]{2}{*}{0.681} & \multirow[t]{2}{*}{0.409} \\
\hline & No & 38 & 45.8 & 45 & 54.2 & & \\
\hline \multirow{2}{*}{ Meningitis } & Yes & 98 & 50.5 & 96 & 49.5 & \multirow[t]{2}{*}{3.548} & \multirow[t]{2}{*}{0.060} \\
\hline & No & 1 & 14.3 & 6 & 85.7 & & \\
\hline \multirow{2}{*}{ Varicella } & Yes & 55 & 52.4 & 50 & 47.6 & \multirow[t]{2}{*}{0.860} & \multirow[t]{2}{*}{0.354} \\
\hline & No & 44 & 45.8 & 52 & 54.2 & & \\
\hline \multirow{2}{*}{ HPV } & Yes & 55 & 52.4 & 50 & 47.6 & \multirow[t]{2}{*}{0.860} & \multirow[t]{2}{*}{0.354} \\
\hline & No & 44 & 45.8 & 52 & 54.2 & & \\
\hline
\end{tabular}

Statistically significant results are reported in bold. ${ }^{*}$ Chi-squared test, significance level $p<0.05$.

\section{Discussion}

In this historical moment of reluctance to immunization, the quality of information sources plays a pivotal role in supporting trust in healthcare workers and health systems.

Investing in information sources could have a positive impact. For this reason, in our analysis, we wanted to investigate the characteristics of those who use institutional information sources and how these later influence risk perception.

In fact, as previously described in Table 2, we found that some socio-demographic characteristics are more strongly associated with a poor use of institutional information sources; in particular, we found that nulliparity is statistically very rarely associated with the use of institutional information sources compared with those who have already had at least one pregnancy.

Women in the first pregnancy have not yet experienced the search for information; we can suppose that in this phase the woman is more concentrated on the pregnancy itself and on the imminent delivery than on future vaccinations. Noteworthy, accordingly to the literature, mother's hesitancy decreases during the first two years after child's birth for an increased maternal experience about vaccinations [21].

The interviewed foreign women, representing $7 \%$ of our sample, had a lower probability of using institutional sources than the Italian ones; maybe the cultural barrier makes less easy to find information and entails a probable lower inclination to access to health care services.

In the literature, the impact of education level on immunization coverage is ambiguous [22-24]. In our case, we found that low schooling is associated with less research for information from institutional sources compared to those who have at least a high school diploma.

Regarding the perception of the diseases' danger, we found that this is significantly related to the quality of the information sources. A similar analysis has been conducted and it has shown that the sources of information influence the level of knowledge of the pregnant women [19].

Regarding single vaccine-preventable diseases, we found statistically significant association only for poliomyelitis, Haemophilus influentiae type b, diphtheria, pertussis and rubella. It is worrying that, in both groups of the population, some diseases, still very widespread such as measles, have not given significant results. This phenomenon may perhaps be attributed to the fact that some diseases are linked to a personal experience of low severity such as measles and chickenpox. But, on the other 
hand, poliomyelitis and diphtheria still frighten women despite being almost eliminated/eradicated. Poliomyelitis in fact still has a high media echo despite its low spread. The lack of statistical significance associated with the perception of dangerousness of meningitis between the two groups, could be attributed on one hand, to the media's echo that it has had in recent years. In fact, as happens during epidemic events, even during the recent meningitis emergency in Tuscany [25,26], it led health authorities to use also the mass media as institutional channels (which in our study were classified as "not institutional") for their rapidity and capillarity to reach the population. On the other, it could be attributed to the intrinsic high outrage level of meningococcal diseases, as recently evidenced [27].

\section{Conclusions}

Women, and mostly when they are pregnant, are sensitive subjects to the issue of vaccination as they are more vigilant to the health of their children. During pregnancy it is important to take advantage of the frequent contact the women have with health professionals to convey correct information. This assumes that health professionals must be aware of factors influencing immunization compliance. In fact, knowing the socio-demographic characteristics of future mothers and the quality of the used information channels may guide to the correct choice of communication. In the future is desirable that health authorities increase also the use of non-institutional sources to convey evidence-based information in order to reach the majority of people.

Author Contributions: Conceptualization, G.G. and R.S.; Data curation, U.C., D.G., G.M. (Giulia Masetti), G.M. (Giulio Matteo), P.P. and A.S.; Formal analysis, U.C., D.G., G.M. (Giulia Masetti), G.M. (Giulio Matteo) and P.P.; Investigation, R.C. and P.G.; Methodology, R.S.; Supervision, G.G., R.C., P.G., R.S. and A.S.; Validation, G.G. and A.S.; Writing - original draft, G.G.; Writing - review \& editing, U.C., D.G., G.M. (Giulia Masetti), G.M. (Giulio Matteo), P.P., R.C., P.G., R.S. and A.S. All authors have read and agreed to the published version of the manuscript.

Funding: This research received no external funding.

Acknowledgments: The authors declare that no funding or grants were received to carry out the present research.

Conflicts of Interest: Giovanni Gabutti received grants from GlaxoSmithKline Biologicals SA, Sanofi Pasteur MSD, Novartis, Seqirus, Sanofi Pasteur, Merck Italy, PaxVax, Emergent Biosolutions, and Pfizer for being a consultant or taking part in advisory board, expert meetings, being a speaker or an organizer of congresses/conferences, and acting as investigator in clinical trials. Umberto Carioli, Diego Gamberoni, Giulia Masetti, Giulio Matteo, Paola Perrone, Rosaria Cappadona, Pantaleo Greco, Roberta Siliquini, and Armando Stefanati declare no conflict of interest.

\section{References}

1. WHO. The Power of Vaccines: Still not Fully Utilized-Ten Years in Public Health 2007-2017. Available online: https://www.who.int/publications/10-year-review/vaccines/en/ (accessed on 16 September 2019).

2. Centers for Disease Control and Prevention (CDC). Ten Great Public Health Achievements-Worldwide, 2001-2010. MMWR Morb. Mortal. Wkly. Rep. 2011, 60, 814-818.

3. WHO. Global Vaccine Action Plan 2011-2020. Available online: https://www.who.int/immunization/global_ vaccine_action_plan/GVAP_doc_2011_2020/en/ (accessed on 25 September 2019).

4. Datta, S.S.; O'Connor, P.M.; Jankovic, D.; Muscat, M.; Ben Mamou, M.C.; Singh, S.; Kaloumenos, T.; Reef, S.; Papania, M.; Butler, R. Progress and Challenges in Measles and Rubella Elimination in the WHO European Region. Vaccine 2018, 36, 5408-5415. [CrossRef] [PubMed]

5. Consiglio Superiore di Sanità. Piano Nazionale Prevenzione Vaccinale. Available online: http://www.salute. gov.it/portale/documentazione/p6_2_2_1.jsp?lingua=italiano\&id=2571 (accessed on 16 September 2019).

6. ECDC. Monthly Measles and Rubella Monitoring Report. Available online: https://ecdc.europa.eu/sites/ portal/files/documents/measles-monthly-report-may-2019.pdf (accessed on 23 May 2019).

7. Istituto Superiore di Sanità. Copertura Vaccinale in Italia. Available online: https://www.epicentro.iss.it/ vaccini/dati_Ita\#morbillo (accessed on 26 September 2019).

8. Ministero della Salute. Conversione in Legge, n.119. Con Modificazioni, Del Decreto-Legge 7 Giugno 2017 n. 73, Recante Disposizioni Urgenti in Materia Di Prevenzione Vaccinale; Ministero della Salute: Rome, Italy, 31 July 2017.

9. Cartabellotta, N.; Luceri, R.; Cottafava, E.; Mosti, M. Vaccinazioni in Età Pediatrica: Impatto Dell'obbligo Sulle Coperture Vaccinali in Italia; Fondazione GIMBE: Bologna, Italy, 2019. 
10. Ames, H.M.R.; Glenton, C.; Lewin, S. Parents' and Informal Caregivers' Views and Experiences of Communication about Routine Childhood Vaccination: A Synthesis of Qualitative Evidence. Cochrane Database Syst. Rev. 2017. [CrossRef] [PubMed]

11. Smith, L.E.; Amlôt, R.; Weinman, J.; Yiend, J.; Rubin, G.J. A Systematic Review of Factors Affecting Vaccine Uptake in Young Children. Vaccine 2017, 35, 6059-6069. [CrossRef] [PubMed]

12. Jackson, C.; Cheater, F.M.; Harrison, W.; Peacock, R.; Bekker, H.; West, R.; Leese, B. Randomised Cluster Trial to Support Informed Parental Decision-Making for the MMR Vaccine. BMC Public Health 2011, 11. [CrossRef] [PubMed]

13. Stahl, J.P.; Cohen, R.; Denis, F.; Gaudelus, J.; Martinot, A.; Lery, T.; Lepetit, H. The Impact of the Web and Social Networks on Vaccination. New Challenges and Opportunities Offered to Fight against Vaccine Hesitancy. Med. Mal. Infect. 2016, 46, 117-122. [CrossRef] [PubMed]

14. Panatto, D.; Amicizia, D.; Arata, L.; Lai, P.L.; Gasparini, R. A Comprehensive Analysis of Italian Web Pages Mentioning Squalene-Based Influenza Vaccine Adjuvants Reveals a High Prevalence of Misinformation. Hum. Vaccines Immunother. 2018, 14, 969-977. [CrossRef] [PubMed]

15. Ferro, A.; Odone, A.; Siddu, A.; Colucci, M.; Anello, P.; Longone, M.; Marcon, E.; Castiglia, P.; Bonanni, P.; Signorelli, C. Monitoring the Web to Support Vaccine Coverage: Results of Two Years of the Portal VaccinarSì. Epidemiol. Prev. 2015, 39, 88-93. [PubMed]

16. MacDonald, N.E.; SAGE Working Group on Vaccine Hesitancy. Vaccine Hesitancy: Definition, Scope and Determinants. Vaccine 2015, 33, 4161-4164. [CrossRef] [PubMed]

17. Gust, D.; Brown, C.; Sheedy, K.; Hibbs, B.; Weaver, D.; Nowak, G. Immunization Attitudes and Beliefs among Parents: Beyond a Dichotomous Perspective. Am. J. Health Behav. 2005, 29, 81-92. [CrossRef] [PubMed]

18. Attitudes towards Compulsory Vaccination in Italy: Results from the NAVIDAD Multicentre Study. Vaccine 2018, 36, 3368-3374. [CrossRef] [PubMed]

19. Bert, F.; Olivero, E.; Rossello, P.; Gualano, M.R.; Castaldi, S.; Damiani, G.; D’Errico, M.M.; Di Giovanni, P.; Fantini, M.P.; Fabiani, L.; et al. Knowledge and Beliefs on Vaccines among a Sample of Italian Pregnant Women: Results from the NAVIDAD Study. Eur. J. Public Health 2019. [CrossRef] [PubMed]

20. Allegato dati CEDAP anno 2016-SISEPS-E-R Salute. Available online: http://salute.regione.emiliaromagna.it/siseps/sanita/cedap/files/Cedap_Allegato_dati_2016.pdf/view (accessed on 9 December 2019).

21. Henrikson, N.B.; Anderson, M.L.; Opel, D.J.; Dunn, J.; Marcuse, E.K.; Grossman, D.C. Longitudinal Trends in Vaccine Hesitancy in a Cohort of Mothers Surveyed in Washington State, 2013-2015. Public Health Rep. 2017, 132, 451-454. [CrossRef] [PubMed]

22. Brown, K.F.; Kroll, J.S.; Hudson, M.J.; Ramsay, M.; Green, J.; Long, S.J.; Vincent, C.A.; Fraser, G.; Sevdalis, N. Factors Underlying Parental Decisions about Combination Childhood Vaccinations Including MMR: A Systematic Review. Vaccine. 2010. [CrossRef] [PubMed]

23. Tomeny, T.S.; Vargo, C.J.; El-Toukhy, S. Geographic and Demographic Correlates of Autism-Related Anti-Vaccine Beliefs on Twitter, 2009-2015. Soc. Sci. Med. 2017, 191, 168-175. [CrossRef] [PubMed]

24. Smith, P.J.; Humiston, S.G.; Parnell, T.; Vannice, K.S.; Salmon, D.A. The Association between Intentional Delay of Vaccine Administration and Timely Childhood Vaccination Coverage. Public Health Rep. 2010, 125, 534-541. [CrossRef] [PubMed]

25. Stefanelli, P.; Miglietta, A.; Pezzotti, P.; Fazio, C.; Neri, A.; Vacca, P.; Voller, F.; D’Ancona, F.P.; Guerra, R.; Iannazzo, S.; et al. Increased Incidence of Invasive Meningococcal Disease of Serogroup C/Clonal Complex 11, Tuscany, Italy, 2015 to 2016. Eurosurveillance 2016, 21. [CrossRef] [PubMed]

26. Meningite da Meningococco C in Toscana e Lombardia 22/12/2016. Available online: https://www.epicentro. iss.it/meningite/2016 (accessed on 16 September 2019).

27. Dettori, M.; Arru, B.; Azara, A.; Piana, A.; Mariotti, G.; Camerada, M.; Stefanelli, P.; Rezza, G.; Castiglia, P. In the Digital Era, Is Community Outrage a Feasible Proxy Indicator of Emotional Epidemiology? The Case of Meningococcal Disease in Sardinia, Italy. Int. J. Environ. Res. Public Health 2018, 15, 1512. [CrossRef] [PubMed]

(C) 2019 by the authors. Licensee MDPI, Basel, Switzerland. This article is an open access article distributed under the terms and conditions of the Creative Commons Attribution (CC BY) license (http://creativecommons.org/licenses/by/4.0/). 